\title{
1. SOCIAL INNOVATION AS AN ALTERNATIVE NARRATIVE
}

\author{
Pieter Van den Broeck, Abid Mehmood, \\ Angeliki Paidakaki and Constanza Parra
}

\section{THE AMBITION OF THIS BOOK}

I

n a world threatened by several crises, including collapse of ecosystems, hegemony of market thinking over the economy, rolling back of the state, diminution of democracy to moments of election and consensus, concentration of wealth, predominance of global corporative conglomerates, rapidly changing identities and loss of socio-cultural diversity, there is an urgent need of an alternative and persuasive narrative. Although threatened (and often plagued) by various economic-centred instrumentalizations, the theory of social innovation provides such an alternative. This theory combines a critical, profound and holist understanding of societal dynamics with a focus on socially innovative practices, responding to unaddressed needs, empowering the deprived, and changing the social relations. Social innovation encompasses collective action that succeeds in changing the world for the better, by mutually embedding social, economic and ecological systems, recreating solidarity-based community relations, stimulating a fair distribution of resources, establishing regenerative economies, and supporting socio-cultural, discursive and cognitive diversity.

This book aims to introduce the work of a collective of academics on social innovation and socio-political transformation. It offers a critique to the dominance of market-based logics and extractivism in the age of 'caring neo-liberalism'. Calling for systemic change, the authors invite the reader to engage in the analysis and practice of socially innovative initiatives and, by doing so, contribute to the co-construction of a sustainable, solidaritybased and re-generative society. As such, the book intends to offer various interpretations of the interconnectedness of social innovation and socio-political transformation, which are part of a more or less coherent socio-scientific project expressed in shared publications, pedagogies, research projects, training through workshops and summer schools, exchange visits, action-research, and pro-activist practices.

\section{THE NATURE OF THIS BOOK}

This book was originally conceived, along with an international academic conference, to 
celebrate the academic career of Frank Moulaert as a leading scholar in social innovation. The celebratory pitch was later extended to the larger working of the ESDP Network, a group of scholars of all ages and disciplines from across the world, active since the 1980s (see e.g. http://esdp-network.net/). To start with, authors were invited to write about specific aspects of Moulaert's conceptual underpinnings and ESDP Network's empirical work in the wider intellectual thinking, through different forms of expression.

The book has subsequently transpired as a socio-political academic statement endorsed by renowned as well as emerging academics with clear ideas on how to change the world. It is also an introduction to the work of a generation of scholars, keen on social innovation and socio-political transformation, a manual for the engaged researcher, and an invitation to nuanced thinking and acting in the quest for a more egalitarian society. The book encompasses a wide range of topics covered by experts in the field into a collection of research and analyses independent of the conventional academic norms and constraints.

This book expresses a belief in the power of critical reasoning, the need to root collective action in high quality analysis, and the will to connect policy making to research agendas. The analysis is critical, questioning inequalities, exclusionary mechanisms and selectivities, interacting with power relations and power structures. The authors argue for an integrated approach, and a holist understanding and interdisciplinary research in all domains of research and action, assuming that a complex world needs sophisticated understandings. This ambition relates to a deep interest in various - including non-academic - modes of knowledge production and research methodology, covering a

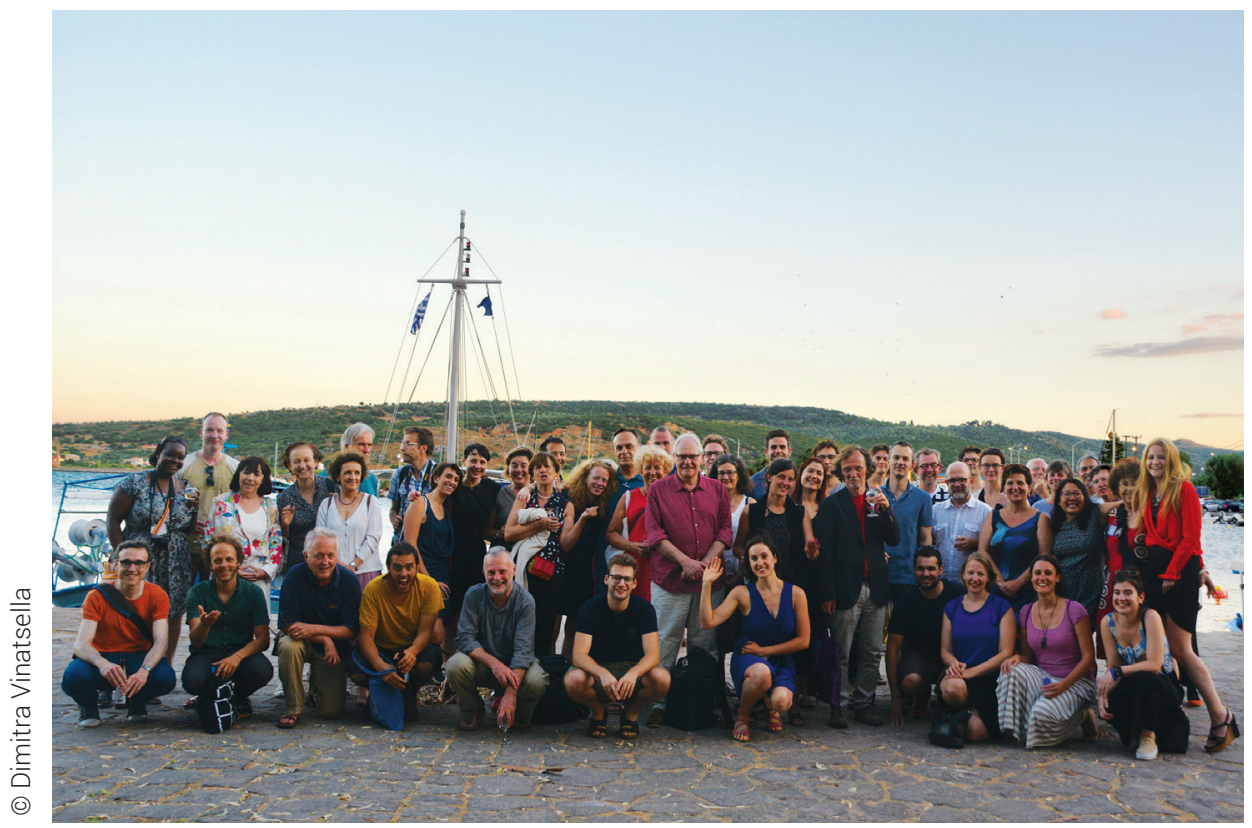


dynamic/ontogenetic perspective on ontology and a critical-realist perspective on epistemology. According to the authors, knowledge is socially constructed. This requires awareness of and reflection on the interaction between researchers and other actors, entailing the need for co-constructed research questions, shared problematizing and theory building, a transdisciplinary approach and careful and engaged action research. Of course, social innovation, as one of the key phenomena and concepts in the work of a majority of the authors, is widely discussed in the book, including the concept's different dimensions, its main underlying research questions and the critique on how the concept has recently been instrumentalized to serve market fundamentalism. The study of how particular social innovations resist the destructive forces of the market and add up to a broader socio-political transformation belongs to the core of the authors' research and action interests, and shows how both strategic action and structural mechanisms need to be understood in their dialectical interactions. This implies a multi-scalar and relational perspective on space and place-making, as applied in numerous analyses of socially innovative case studies.

In sum, this book is a statement, including not only a critique of the age of neo-liberalism challenging the dominance of market-based thinking, but also a call for systemic change. The authors express a worldview that is shared by a large network of academics some of whom have been collaborating for the past thirty years. As such, the book is not only an inspiration for academia in many ways, but also for social movements and their protagonists challenging the dominance of the powers that be and changing the world, and for politicians who want to appreciate the contemporary ways of thinking and get inspiration on how to better attend the needs of the communities they serve.

Finally, this book is a manual for the engaged researcher, which is evident from the critical questions addressed, the critical-realist epistemological approach, the heterodox

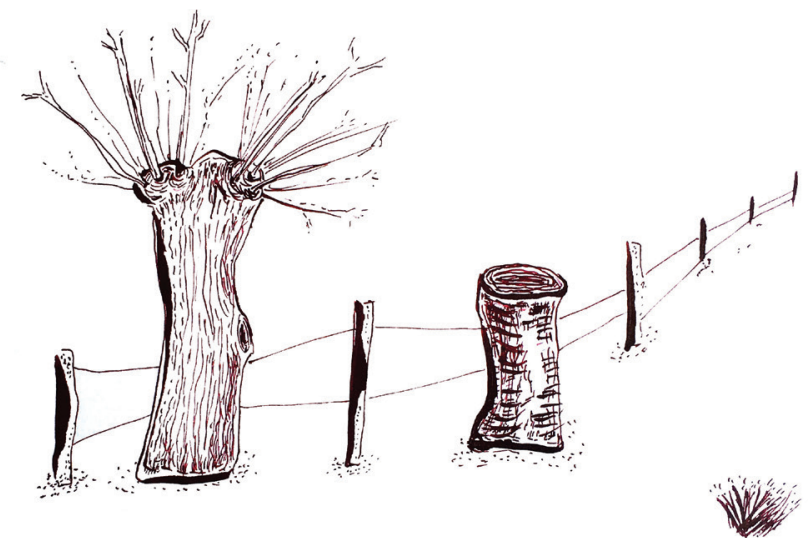


theories that are mobilized, the will to bridge science and arts, the social and the ecological anatomy and action, the attention to solidarity and reciprocity in human relations, the analysis of the needs of all actors, and the empowerment of the underprivileged. Many chapters in the book echo the researchers' concerns about poverty, exclusion, inequality, competition, resource grabbing, the growth fetish, and attempts to forward the market as the main organizing mechanism of our society and the ecosystems it interacts with. As such, the authors invite you to join this endeavour to analyse, reflect on, and act in the world we live in today to co-construct a solidaritybased and regenerative alternative.

\section{ORGANIZATION OF THE BOOK}

To build a consistent, though diverse, overview on social innovation and socio-political transformation, the editors drafted a list of key topics in this field. To do justice to the diversity of the authors' interests, these topics were to be addressed in three different ways - essays, text-boxes and stories - after which particular authors were contacted to offer their contributions. The response was overwhelming. Once all texts were made available, the book was reorganized into 15 thematic sections, showing the variety, complexity and richness of the authors' thinking and practices.

As such, 55 authors contributed to a variety of essays, short explanations and illustrative cases, covering work on: Keynesian economics and regional development; migration; integrated area development; poverty; territorial innovation systems; heterodox political economy; urban regeneration and the new urban policy; governance, social innovation and solidarity; neighbourhoods and communities; culture, arts and social inclusion; spatial development planning; the sociology of knowledge, science-society relations and pedagogy; social innovation, sustainability and socio-ecological systems; underdevelopment and global North-South relations. Most of these contributions combine historical insights, current debates and avenues for the future.

Inevitably, a few topics may be missing. The editors are however confident that the extensive bibliography will enable readers to explore additional aspects of social innovation and socio-political transformation for themselves.

\section{ACKNOWLEDGEMENTS}

Since this book is a collective effort, many people need to be thanked. The editors are grateful to all authors for their spontaneous positive response, high quality contributions to the book and willingness to tune into a concept which might not have been totally clear from the beginning.

Thanks and apologies are due to all who could have been here but were not included due to limited space, and to those who tried but could not contribute due to various reasons. Special thanks go to Diana MacCallum for helping with a 'light-touch' language check 
and a 'proper' bibliography. Thanks to Ruth Segers \& co. for providing the cover picture of this book. Special thanks to Maarten Loopmans for making tailored stimulating sketches and to Els Dietvorst for her wonderful drawings. Last but not least, we are grateful to Flavia Martinelli and Erik Swyngedouw for supporting the project all along.

The publication of this book was possible thanks to the support of the Flemish Agency for Innovation and Entrepreneurship (VLAIO) and their programme SBO for the research project INDIGO by KU Leuven, UAntwerp, Harokopio University and OMGEVING cvba (see www.theindigoproject.be).

Many of the authors wouldn't have been able to spend lifelong careers in critical research if there hadn't been people supporting them. So, the editors, and surely also all authors, thank all those families, friends and relatives bearing with the efforts and time that academic careers unfortunately demand.

Finally, the editors wish to dedicate this book to Isabel André, a good friend of many of the people involved in this project, who sadly passed away on 3 April 2017, during the making of this book. Her draft chapter may be one of the last pieces she wrote, which reflects her passion and commitment. Thank you, Isabel, for everything you have given us. We will continue your work and extend your gentleness. $<$

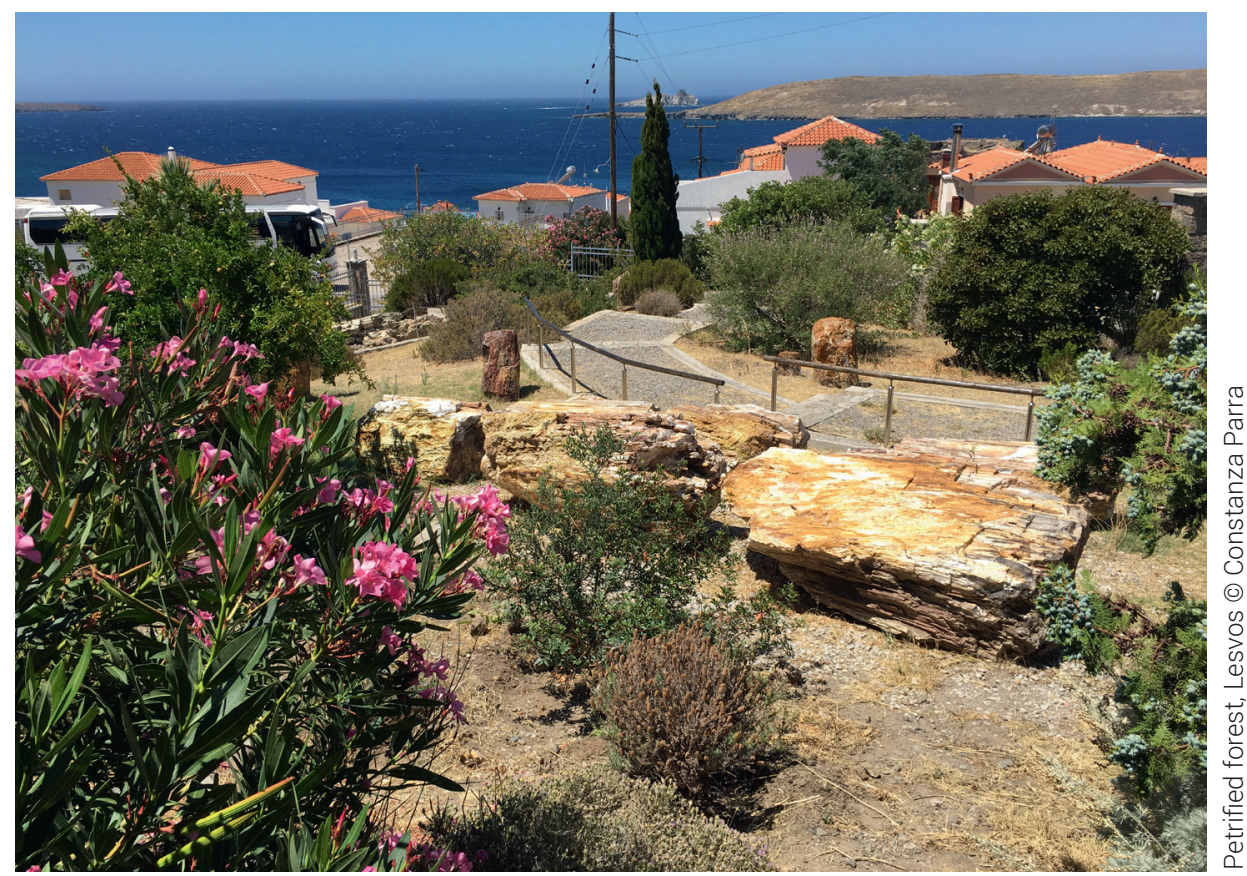

